\title{
Surveying data on connected personal networks
}

\section{Report}

Author(s):

Kowald, Matthias; Axhausen, Kay W. (D)

Publication date:

2011

Permanent link:

https://doi.org/10.3929/ethz-b-000159741

\section{Rights / license:}

In Copyright - Non-Commercial Use Permitted

\section{Originally published in:}

Arbeitsberichte Verkehrs- und Raumplanung 745 


\section{Surveying data on connected personal networks}

Corresponding author:

Matthias Kowald

Institute for Transport Planning and Systems (IVT)

ETH Zurich

Wolfgang-Pauli-Str. 15

HIL F 51.2

CH-8093 Zurich

kowald@ivt.baug.ethz.ch

Co-author:

Kay W. Axhausen

Institute for Transport Planning and Systems (IVT)

ETH Zurich

Wolfgang-Pauli-Str. 15

HIL F 31.3

$\mathrm{CH}-8093$ Zurich

axhausen@ivt.baug.ethz.ch 


\section{Abstract}

This survey study combined name generators with snowball sampling to collect information on personal leisure networks and underlying "global" network structure. Although such an arrangement is not unusual, this large-scale study - with around 700 respondents - reported nearly $15^{\prime} 500$ social contacts. Furthermore, snowball chains were limited to leisure contacts with no further limitation on collecting data or continuing recruitment.

While our methodological frame allowed analysis of both personal and global network structure within one data collection, it also included several sources of bias. To decrease bias, the study employed several especially designed mechanisms.

The paper examines both survey methodology and instrument in detail. We discuss tools to decrease bias and statistics on their possible impacts, with rather surprising results. The paper closes with a discussion of data security issues and ethical considerations: important factors in projects using such methodologies. The Swiss Swiss Federal Data Protection and Information Commissioner evaluated this study, making this section particular interesting for those planning similar projects.

\section{Acknowledgements}

The authors acknowledge Eleanor Wittmer, Inna Skhodrova, Nina Otter, Nathalie Schenk, Benjamin Belart, Raisa Galimova, Fritzi Hartung-Hoffmann, Johanna Jochum, Sambasivam Nilanthi, Martin Roeck, Till Richter, and Daniel Knuchel, who worked as student assistants in this project. Without their efforts in recruitment, the survey would have been impossible. In addition, we acknowledge the work of Christoph Dobler, ETH Zurich, who designed the electronic questionnaire, which we did not ultimately use. However, the instrument was used to code the paper questionnaires in electronic form. Information on this instrument will be provided on request. It also should be mentioned that an earlier version of this paper was presented at the $9^{\text {th }}$ International Conference on Transport Survey Methods (ISCTSC) in Termas de Puyehue in November 2011. 


\section{Leisure travel and social network analysis}

Leisure-oriented travel is an important travel segment in western societies, in both time and miles spent on these trips. However, explaining leisure travel is challenging because it is different from other forms of travel: it is strongly influenced by external factors like weather conditions and social contacts and thus sporadic, while other kinds of travel, e.g. commuting, are often driven by constant needs (Schlich et al., 2004). To investigate the influence of social contacts on leisure travel patterns, numerous studies in transport planning used social network analysis (SNA) methods in recent years. They identified leisure travel as being primarily undertaken to join others in leisure activities; it is also referred to as 'social' or 'activity' travel. In focusing mainly on network topology statistics (i.e., number of personal contacts, geographical distances between tied persons, and contact modes and frequencies used to maintain relationships), these projects confirmed SNA-methods productivity, producing new empirical insights and results (see Larsen et al., 2006; Carasco 2006; Silvis, 2006; Frei and Axhausen 2007; Van den Berg et al., 2007). In addition, the projects offered insights into challenges in data collection and modeling (Hogan et al., 2007; Frei and Axhausen, 2008; Carrasco and Miller, 2009; van den Berg et al., 2011; Arentze et al., 2011). However, one issue was ignored by previous studies: topology of a population-wide 'global' leisure network. Information on this structure is needed to allow analyses on network structures underlying personal networks as well as an implementation of a 'global' leisure network in agent-based travel demand simulations.

The Institute for Transport Planning and Systems (IVT) of ETH Zurich and the Institute for Sea- and Land-Transport (ILS) of TU Berlin conducted a joint survey study between January 2009 and March 2011 to investigate this global leisure network topology. This paper introduces the survey in detail. Chapter 2 discusses different methodological options to focus on global networks and describes the design chosen. Chapter 3 introduces the survey instrument and discusses selected features. Survey protocol, closely linked to bias-decreasing measures developed for this project, is presented in chapter 4. Relevant ethical and data protection issues are addressed in chapter 5 . Finally, major results are summarized in chapter 6.

Survey methodology, instrument and aspects of survey protocol were described in earlier papers and conference presentations, available at the Homepage of the Institute for Transport Planning and Systems (IVT) of ETH Zurich (Kowald, Hackney and Frei, 
2008; Kowald, Frei and Hackney, 2008; Kowald, Frei, Hackney, Illenberger and Axhausen, 2009a; Kowald, Frei, Hackney, Illenberger and Axhausen, 2009b; Kowald, Frei, Hackney, Illenberger and Axhausen, 2009c; Kowald and Axhausen, forthcoming; Kowald, 2010; Kowald, Frei, Hackney, Illenberger and Axhausen, 2010; Kowald and Axhausen, 2010a; Kowald and Axhausen, 2010b; Kowald and Arentze, 2010; Kowald and Axhausen, 2011). However, these papers presented preliminary results because the survey was still in the field when they were written. Furthermore, they focus on a few selected aspects, or discuss subjects in a broad overview. In contrast, this paper introduces all relevant methodological and fieldwork aspects and discusses them in relation to each other. Importantly, it was written after fieldwork was completed, with results based on the final sample.

\section{Connected personal networks: Survey methodology}

The term 'social networks analysis' does not refer to one fixed method of collecting and analyzing data, but to a whole set of methods; an appropriate choice must be made according to project goals (Wasserman and Faust, 2007; Scott, 2007). Basically, SNAmethods allow focus on interacting actors, e.g. people, companies, or countries, and their ties at the same time; a tie is defined by whatever is circulating in the network, e.g. information, money, or simply willingness to spend free time together. So, explanations can consider actors' characteristics and their social environment. One sees how social structures, emerging from interactions, provide both opportunities and constraints for actors' activities. For our survey study's aims, tools to collect two types of information were necessary: first, data on peoples' individual leisure network to replicate and enhance analyses from former studies and allow for comparisons and second, data on these individual network structures' embedded nature in a population-leisure relations network.

Social relationships cannot be sampled per se; SNA-methods suggest using samples of actors for observation or questions about their relationships (Knoke and Kuklinski, 1982). Leisure networks are normally developed over time, influenced by decisions like retaining or losing contact. These structures are individual; people can move physically and socially throughout their lives, relatively unfettered by institutional settings like companies, municipalities, or even national borders. Given these factors, the 'personal network approach' was used to survey leisure networks. It focuses on social environment, here in terms of leisure contacts, and allows a survey of information about representative population samples, which often facilitates generalization of survey results. 
The counterpart to surveying personal networks is the 'full network approach', where all actors and relations in an institutional setting are observed. This approach results in a comprehensive network structure picture and is only feasible for small populations (Marsden, 1990).

When aiming for a population-wide network, the personal network approach has a serious disadvantage. Usually, studies on personal network structures seeking valid inferences recruit respondents from random samples. Participants (the survey population), are, therefore: 1.a subset of the frame population, including all people in the initial random sample from which they are recruited and 2.an even smaller subset of the target population, defined as all individuals studied for whom inferences should be valid (Groves, 2004). This size difference between survey and target population and smaller personal leisure networks, - averaging around 15 contacts as former studies showed (Larsen et al., 2006; Carasco 2006; Silvis, 2006; Frei and Axhausen 2007; Van den Berg et al., 2007) - makes overlap between personal network structures (two respondents either mentioning each other as social contacts or sharing a social contact) unlikely. In fact, no previous transport planning studies observed such overlaps; they all focused on isolated personal network structures (for an illustration see figure 1a).

A picture of a population-wide leisure network can be obtained by employing one of two survey methodologies. First, 'saturation sampling' can be used, meaning all individuals in the relevant social structure are interviewed about their social relationships. Similar to the full network approach, this is feasible only for small target populations. The alternative is employing a link traced sampling methodology to survey information on personal networks and connections between those structures (Coleman, 1958; Gabler, 1992). Although there are several 'chain methods' (for a general discussion see Erickson, 1979), they all ask some initial respondents for their social contacts and then use these contacts to continue recruitment. Depending on the method chosen, certain statistical features of the overall network structure can be calculated. The best-known chain methods are 'snowball sampling' and the 'small world method'.

Small world experiments use messages, e.g. letters or E-Mails, that must reach predefined recipients (see Milgram, 1967; Kochen, 1989; Schnettler, 2009a). Participants are asked to either pass the message to the recipient directly, or to a person who would be able to forward it to the recipient. So, the experiment asks participants to use one of their social contacts to forward a message. This allows for estimation of average path length between two randomly chosen individuals within a population. One problem 
with this approach can be actors' limited information on their social environment. Because they lack knowledge about overall network structure and possible shortcuts, chain lengths are often overestimated (Kleinberg, 2000; for an illustration, see figure 1b). Another problem results from questions on how to deal with disrupted contact chains that did not reach their destination (Schnettler, 2009b).

In comparison to a small world experiment, snowball sampling uses several of the respondents' social contacts to continue recruitment. These persons are then again asked to mention their social contacts. This is repeated for a predefined number of iterations and results in a sample where former respondents mentioned all respondents, on each iteration level (except initial ones). This next group of respondents then introduces frame population names of the following iteration level. Each initial respondent, called a "seed", makes up a component of directly or indirectly connected personal networks. Depending on the relation between survey and target population, overlaps between components are rare, a problem similar to surveying isolated personal networks employing the personal network approach without snowball sampling (see figure 1c; for a schema of a snowball component with four iteration levels, see figure $1 d$ ).

To summarize, snowball sampling benefits from the personal network approach - surveying information on personal networks in a large population - by avoiding exclusive focus on isolated network structures. Because only a few seeds are needed to find other members of a population, snowball sampling and other forms of link traced sampling methods can also be used to survey information on hidden or hard-to-reach populations. To collect data on connected actors, sociological (Schweizer et al., 1998; Saletin, 1999), anthropological (Jones, 2003), and medical studies (Mathews et al., 2001) use snowball studies. However, one must be aware that snowball samples include three major sources of bias. 
Figure 1 Graph: 1a) isolated personal networks in population; 1b) population and small world; 1c) population and snowball sampling; 1d) schema snowball sampling

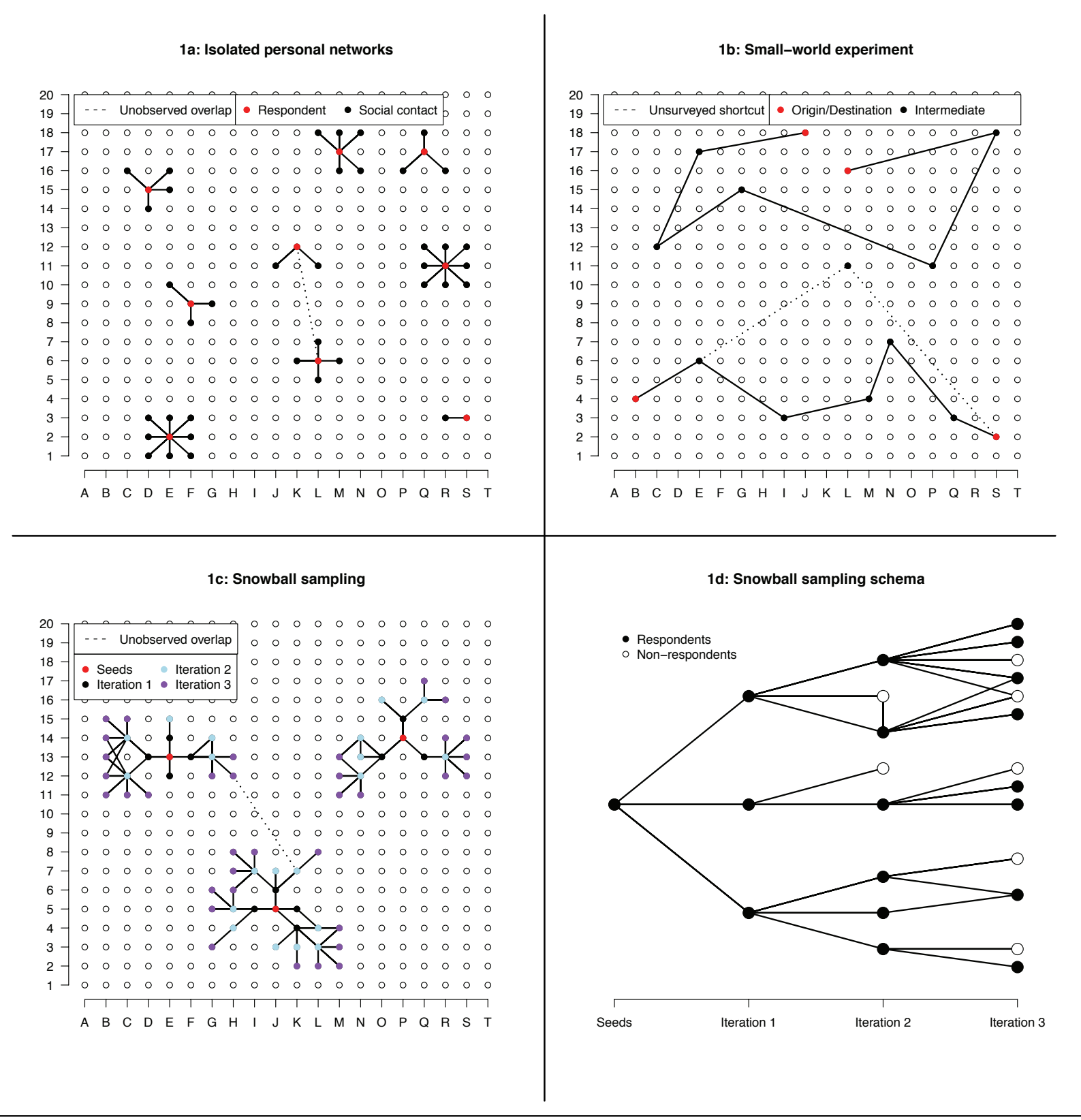

Initially, snowball sampling barely meets randomness criteria. Former respondents select all persons on the iteration levels, unlike the seeds, who can be recruited from a representative random sample. This 'selection bias' results in unequally distributed probabilities for people to become part of the sample. Increasing response rate and surveying respondents' social contacts as completely as possible can help minimize selection bias. Although social contacts are still mentioned selectively, a complete personal network structure and high response rate can help to survey a valid picture of the 
variability of personal network structures. To reach this goal, respondents must feel confident about participating and mentioning their leisure associates. Furthermore, in snowball sampling, control should be maintained over snowball chains (when recruiting social contacts) in researchers' hands after experience with a study where respondents themselves were asked to recruit their social contacts, resulting in serious problems (see Silvis et al., 2006; for similar designs where respondents are asked to recruit their contacts see Heckathorn, 1997).

The second kind of bias deals with the well-documented phenomenon of homophily, describing a similarity between directly connected persons, whether in sociodemographics or in behavioral patterns (see e.g. McPherson et al., 2001). 'Homophily bias' poses a challenge for the survey methodology; the sample should ultimately represent the socio-demographical heterogeneity of its target population. However, when directly connected persons are similar to each other, seeds should be selected carefully to reproduce target population variability.

Finally, the snowball method oversamples respondents with larger network structures than average. The more relationships a person has, the higher the probability that this person is asked to participate via one of these communication channels. A team at TU Berlin developed an estimator to correct this 'degree-bias'. The method weights reported network sizes with their estimated occurrence frequency on each iteration level (for details and references to earlier work on this problem, see Illenberger and Flötteröd, 2011).

The snowball sampling approach was chosen to satisfy the study aims. To decrease bias, it employed several mechanisms. Chains were started with 40 seeds. Continuing with their social contacts, the study collected information on nearly 700 respondents and their approximately 15,500 social contacts. Project relations between respondents and their social contacts were limited to leisure contacts to best suit the project topic. Researchers imposed no further limitations. Social contacts could live anywhere, did not have specific characteristics or use specific communication channels. To our knowledge, a snowball sampling driven study of this size, with so few restrictions, has never been attempted in the field. 


\section{Collecting data: Survey instrument}

The design of a survey instrument is, among other factors, influenced by the investigation topic, requirements resulting from survey methodology, and attempts to assure easy participation and keep response burden low. 'Contact diaries' or 'name generators' usually collect personal networks data. In both methods, respondents are also referred to as 'egos' and their social contacts as 'alters'. A name generator is a question that employs stimuli to focus respondents on the part of their social network of interest to a study, rather than collecting information on the entire personal network structure, including all contacts. (Marsden, 1990; Campbell and Lee, 1991; Wolf, 2004). While contact diaries can use such a limitation as well, they always imply an additional time boundary limiting the requested period (Fu, 2007). When surveying information on leisure contacts without further limitation, e.g. in time, institutional setting, or communication modes, the name generator approach was preferable to a diary.

The survey instrument had four sections designed to collect detailed information on egos' and alters' personal characteristics and topologies of personal leisure networks. The first section asked for respondents' characteristics, their socio-demographics, and mobility biography (residential and working places throughout their lives).

The second section included two name generators. To survey the specific network as completely as possible, several name generators should be used, providing multiple stimuli. Because name generators ask egos to self-report their network structures, numbers of social contacts can be inaccurately reported, caused by forgetfulness, omission, concealment, or invention of alters (Bell et al., 2007). An unsupported collection of network members is thus inadvisable (Pool and Kochen, 1978). Furthermore, number of reported contacts is directly influenced by number of name generators and space provided to write them down. Instruments including only one name generator (for popular studies, see Wellman, 1979; Marsden, 1987) are usually biased, because the reported network structures are rather small. However, multiple name generators (the instrument used by Fischer, 1982 is very popular) can also result in bias (for a comparison of name generators and resulting network size, see Frei and Axhausen, 2007). Possible effects include: fatigue, where people report smaller numbers of contacts the later a name generator question appears, and satisficing where people stop mentioning names when they feel they have reported enough social contacts. Furthermore, multiple questions can result in bias from cognitive priming, when one stimulus overlies a later one, or the more general effect of question-scope redefinition, where former 
questions influence later ones (see Pustejovsky and Spillane, 2009). A compromise is the multiple name generator developed by Marin and Hampton (2007), which uses a moderate number of questions, with each question providing certain stimuli. Following Marin and Hampton's suggestion, the first name generator of the snowball study asks explicitly for leisure contacts by providing several behavioral stimuli linked to leisure interactions. These stimuli distinguish clearly whether a relationship fits one of the criteria or not. The second name generator uses an affective approach by asking respondents with whom they discuss important problems. This question seeks emotionally important contacts, using a contextual situation with differing possible interpretations instead of interaction stimuli; it could be somewhat imprecise. However, both kinds of social contacts can trigger leisure travel and are important for the study; thus, both name generators were employed.

In all, space to report up to 40 names was provided. The first name generator was placed above this space, the second one below. This design was chosen after a pre-test with a different design, where the first name generator provided space for 29 names and the second for 11 additional names. This first design resulted in fatigue and satisficing effects, with a clearly visible artifact in the distribution of reported social contacts. Because many respondents reported 29 names in the first question and none in the latter, the design had to be changed to avoid bias. The re-design (figure 2) solved this problem; the number of reported social contacts increased, on average, although it also had a negative effect. As respondents were asked to report their acquaintances for both questions in the same space, the ability to distinguish between the two kinds of social contacts was lost. Respondents who wanted to report more than 40 contacts were asked to write them down on an extra sheet of paper, so that, in principle, the number of names was unlimited. Still, we assume that at least some respondents refused to make this additional effort due to fatigue or similar issues. Therefore, only the first 40 names were considered for analysis. Furthermore, respondents were not asked to report contacts that fit in both generator categories. This helped to decrease response burden but also sacrificed the possibility of multi-relational analyses. 
Figure 2 Name generators

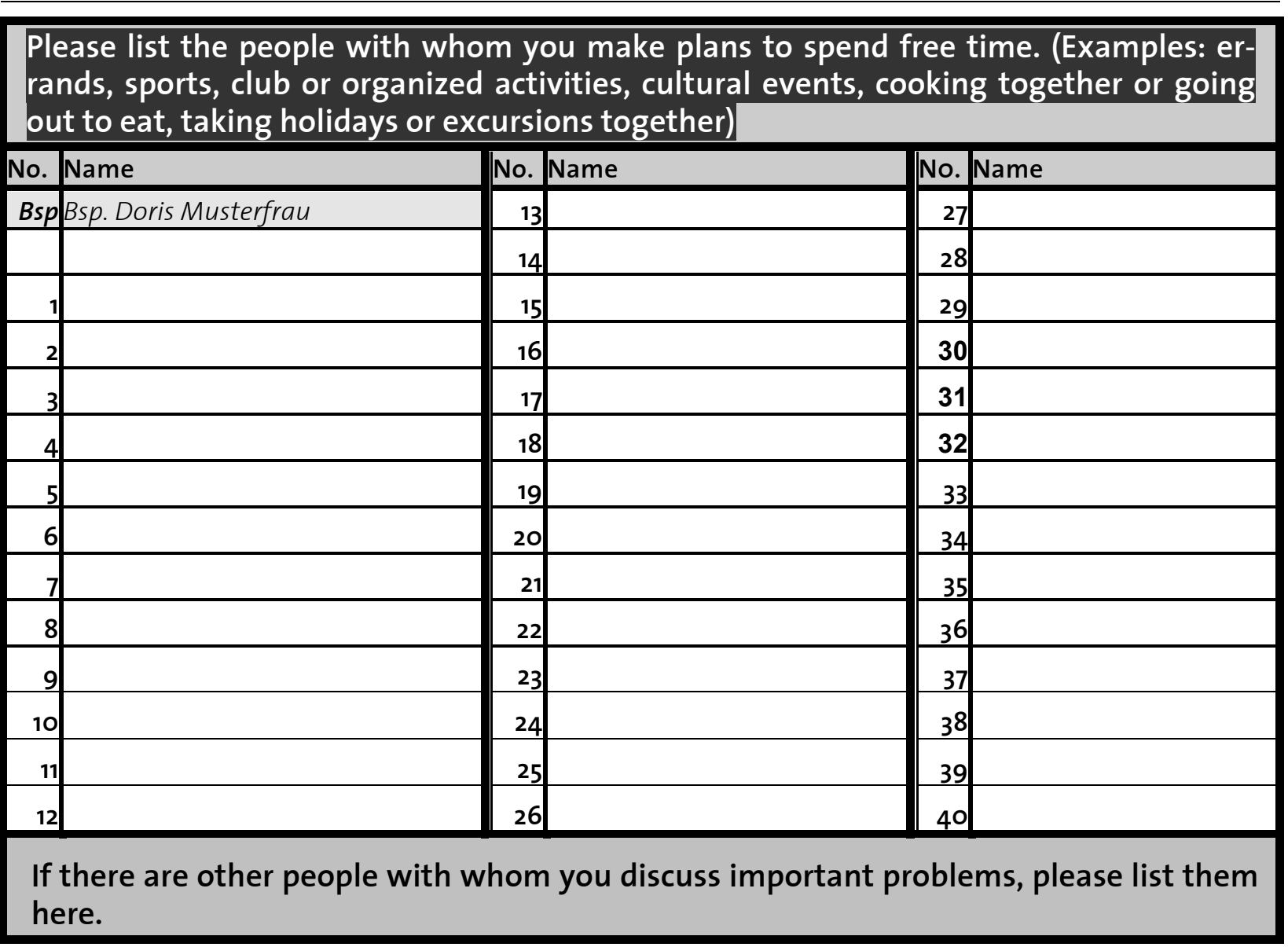

The third survey instrument section was a 'name interpreter', asking egos to report some basic socio-demographics of each alter mentioned in the name generator and some information on the ego-alter relation, e.g. duration and circumstances of first meeting. Due to the ascending nature of snowball sampling, the instrument also collected information on social contacts' addresses. Participants not wishing their network members to be contacted for further recruitment were asked to write this down, or to use anonymous nicknames for their alters. The name interpreter also included a check box, which respondents had to mark if they wanted to stay anonymous in further recruitment. This meant they did not wish their alters to know who mentioned their names.

The fourth and last section of the instrument was a 'sociogram', asking respondents to mention those social contacts from the name generator who make plans to spend free time together. Sociograms show a wide range of diversity, from socio-matrices, which ask egos to mark any pair of alters that have a certain kind of relation, to visualizations, measuring different kinds of relations and their emotional closeness. They can be used 
as a form of a name generator (see Hogan et al., 2007) or in addition to a name generator, which is the case here. While socio-metrical tables are often considered boring and result in fatigue effects, graphical elements imply theoretically driven categories, which can influence respondents' answers (Mamali, 2006) The snowball study sociogram was designed to collect information on cliques within the personal network topologies specifically alters making plans to spend free time together. This snowball study dealt with people all over the world; an interviewer could not always be present, meaning that the design had to allow easy participation. The current design addressed these requirements by asking respondents to mention contexts in which their social contacts meet, e.g. birthday party or hiking group, and to list all alters joining one of these meetings regularly. To reduce response burden, names could have been reported with the help of a predetermined shortcut from the name generator. However, respondents were not allowed to mention any social contacts beyond those reported in the name generator. While this kind of sociogram allows easy participation, it automatically results in fully connected clique structures. It implicitly assumes that all alters joining one leisure group known to ego are also fully known to each other. The assumption of fully connected cliques is thus a potential source of bias, particularly significant in a large clique. Nevertheless, the present design is a good starting point for leisure network topologies: as almost all cliques are rather small, presumably an accurate one as well. Respondents were allowed to mention up to 20 cliques; thus, each alter could have been a member in more than one clique.

All questions in the instrument were formulated in a clear, easy understandable and unambiguous way. Furthermore, examples were given wherever questions could have caused problems. This supported respondents in comprehending, judging, and finally answering the questions (see Groves et al., 2009; for detailed information on developing and pre-testing the survey instrument see Kowald et al., 2009b). The survey instrument was issued exclusively as a paper version in German and English. Although an electronic version was available, it was not used in the snowball process because of doubts about function with various browsers. In addition, lower response rates (Sen and Bricka, 2009), and higher rates of drop out behavior and item non-response are reported for online instruments (Heerwegh and Loosveldt, 2008; Couper and Miller, 2008; for problems with online surveys on personal networks see Matzat and Snijders, 2010). Given these issues, we decided to keep high technology in the lab and use low technology in the field (Hogan et al., 2007).

\section{Reducing bias: Survey protocol}


Taking a snowball sample without geographical limitation means that respondents and their social contacts could live anywhere. Thus, one particular snowball sampling challenge is defining the inference population for which the sample should be valid. Chains were started in Canton Zurich, Switzerland and previous studies showed that most leisure contacts are local or regional (Frei and Axhausen, 2007). So, it was expected that egos and alters would be clustered in Switzerland, which indeed was observed; both target and inference population are identical with the Swiss population.

Employing snowball sampling and name generators introduced several issues of bias. In order to decrease bias, the study adopted several measures: one related to the fact that snowball sampling uses only a few seeds to start its chains. According to the statistical law of large numbers, this can result in bias, as there is no guarantee that these few seeds represent target population characteristics, even when recruiting from a random sample. To improve chances of covering at least some personal characteristics distributions properly, the survey used a stratified random sample of the Canton Zurich population to recruit its seeds. This part of Switzerland was chosen because it exemplifies Swiss population heterogeneity and includes urban and rural areas. The sample was stratified in terms of sex and age and matched the share of people living in urban or rural environments. While over- or under-sampling bias is already a problem when employing 'usual' sampling techniques, it is even worse for snowball sampling. Due to a frequently observed similarity between respondents and their social contacts, this bias might not only be passed on from iteration to iteration, but even increase during this process, a phenomenon we called 'homophily-bias' earlier. To have a chance of balancing homophily-bias, the sample employed a low-tech measurement: snowball chains were started in two consecutive sub-samples. Each sub-sample used 20 seeds. After data collection on the final iteration level was completed for sub-sample 1, data were analyzed to see if the sample was captured in a homogenous cluster. Recognizing that this had indeed occurred with egos' ages triggered the decision to start the second sub-sample by selecting younger seeds. Ultimately, this helped to balance bias and cover the Swiss age distribution more accurately, as shown in table 1. 
Table $1 \quad$ Using consecutive sub-samples to balance sampling bias

\begin{tabular}{|c|c|c|c|c|c|c|c|}
\hline \multirow[t]{2}{*}{ Age categories } & \multicolumn{2}{|c|}{ Egos Sub-sample 1} & \multicolumn{2}{|c|}{ Egos Sub-sample 2} & \multicolumn{2}{|c|}{ All alters } & \multirow[t]{2}{*}{ Micro-census } \\
\hline & $\%$ obs. & $\varnothing$ age & $\%$ obs. & $\varnothing$ age & $\%$ obs. & $\varnothing$ age & \\
\hline $0-20$ & 0.9 & 18.0 & 0.4 & 19.5 & 3.0 & 14.8 & 13.3 \\
\hline $21-40$ & 17.9 & 33.4 & 17.6 & 32.3 & 22.0 & 32.5 & 31.4 \\
\hline $41-60$ & 35.4 & 49.8 & 63.1 & 49.6 & 49.8 & 49.6 & 49.9 \\
\hline $61-80$ & 42.4 & 68.9 & 17.8 & 66.8 & 22.8 & 68.1 & 69.4 \\
\hline $81+$ & 3.5 & 82.3 & 1.1 & 83.0 & 2.4 & 84.4 & 84.6 \\
\hline
\end{tabular}

Source: Micro-census data taken from ARE/BfS, (2007)

Seeds were important for another reason as well. Asking them to fill out the instrument with the help of interviewers was an attempt to improve data quality and create a basis for comparison with data collected by mail questionnaires on later iteration levels. Interviewers were trained to ask the name generators questions repeatedly to make the seeds mention their contacts completely.

This is related to the second major bias concern: uncertainty whether respondents mention all their leisure contacts and whether these contacts can be recruited as completely as desired. In other words: studies combining snowball sampling and name generators should include measures to give respondents confidence when mentioning their contacts. This helps decrease selection bias and increases response rates to obtain a more complete picture of the underlying global network structure.

Textbooks on quantitative research studies suggest using a 'multi contact strategy' to establish and maintain contact between potential respondents and the research team (Dillman, 2000). This proves researchers' interest and efforts in collecting data. Furthermore, each contact can be a source to inform respondents about study aims, issues regarding their anonymity, their status as volunteer participants and how to handle the survey instrument. Following up on this idea, the study employed an announcement letter, a recruitment call, an accompanying letter sent with the questionnaire and a prepaid envelope to return the instrument, a remainder letter for those who did not return the survey instrument within three weeks (if needed), and, finally, a thank you letter. In addition, a web page (http://www.soziale-kontakte.ch/index_EN, August $12^{\text {th }}$, 2011) was designed providing detailed information on the survey, the research team, 
and links to all publications resulting from the project. Besides documenting researchers efforts in collecting data, both multi contact strategy and web page increased the transparency of the study, created a trustworthy atmosphere and made potential respondents feel confident about participating. All contacts employed mechanisms from rational choice theory. Both multi contact strategy and web page tried to prime potential respondents in a normative way. Asking for help in developing a new scientific approach emphasized the study's scientific character. Assuming that people are often primed in a hedonic way, this shift increased the probability for potential egos to take on the response burden and fill out the questionnaire (for detail on goal framing theory see Chartrand and Bargh, 1999, Lindenberg, 2006, 2008; Aarts et al., 2004).

Furthermore, we instituted a measure to express appreciation for respondents' efforts in filling out the survey instrument. Following the idea of a so-called 'gratification strategy', 20 CHF (or the equivalent amount in the currency of potential respondents' residence country) were sent with the survey instrument. This sum seemed fair, as the survey instrument included substantial response burden and most respondents lived in Switzerland, where 20 CHF could fund, e.g. an evening in a cinema. Money was preferred to non-monetary gifts or gift certificates, as this kind of appreciation is understood universally. Whenever a gratification strategy is used, the token should be sent with the survey instrument to boost the response rate. Dillman (2000) argues that the appreciation transforms the situation between potential respondents and research team into a social exchange, functioning as social approval given in a symbolized form, encouraging people to behave in a normative, rather than a hedonistic, way (Frey, 1997; Diekmann, 2001). However, sending a token after the fact usually does not produce significant results; it is more of an economic exchange, which would be like paying respondents for their participation. Regarding gratification strategy, it must be mentioned that respondents understood their participation was voluntary and, of course, non-respondents were allowed to keep the token without any pressure or obligation. They did receive a reminder letter asking them again to participate, but the token was not mentioned.

Finally, the survey included a chain method-related strategy to increase response rate. Using previous respondents to recruit new participants is a strategy in respondentdriven sampling, where respondents receive a token for filling out the questionnaire and a second one for recruiting their social contacts (Heckathorn, 1997. Here, egos were asked to fill out a prepared greeting postcard and either return it to the survey team, or send it to their alters. This card confirmed to potential respondents that a trusted con- 
tact had already participated in the study, increasing the chances of participation. In other words, the card was an attempt to initialize goal contagion behavior, which is the strategy of copying behavior, often observed between closely related persons. Both effects, achieving a normative frame and goal contagion, are extraordinarily strong when occurring together (Cialdini et al., 1990). When respondents used the cards, they lost their anonymity in the recruitment process, meaning that their alters were able to ascertain who mentioned their names. This was the case for around 10\% of all alters. However, if respondents did not use the cards, they remained anonymous in further recruitment.

Figure 3 Survey protocol and greeting postcard
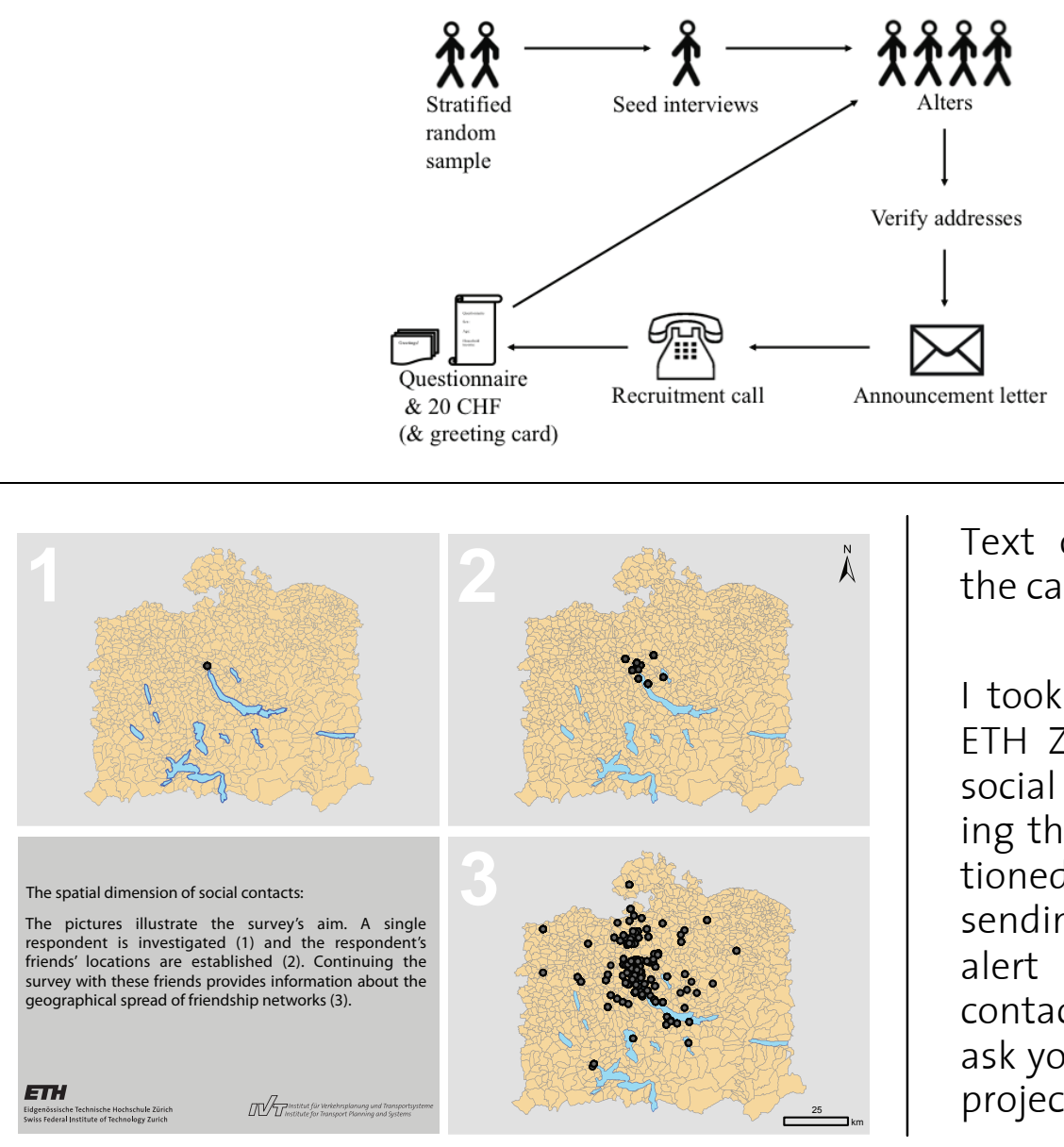

Text on the backside of the card:

I took part in a survey of ETH Zurich regarding my social network. In answering their questions I mentioned your name. I'm sending you this card to alert you that ETH will contact you and also to ask you to take part in the project.

The snowball methodology necessitated checking all names to avoid re-sampling, which could have happened when egos mentioned alters already in the sample. Avoiding re-sampling was also necessary for an accurate picture of the underlying global network, or re-sampled persons would have been captured as two different individuals. Student assistants did this work by comparing names and postal addresses. The com- 
bination of multi contact strategy, incentive, and name comparisons was time consuming and resulted in survey costs of around $110 \mathrm{CHF}$ per respondent.

These measures helped increase response rate. Overall, the survey achieved a response rate of around $26 \%$ (calculated as the RR1, valid addresses divided by participants, as suggested by AAPOR (20011)). Details of recruitment are provided in table 2, which shows that the recruitment process was stopped at iteration 4 . Table 2 also shows many social contacts as re-identified. These alters were mentioned as social contacts by different egos. Significant resulting overlaps in network occurred both between egos within one component and between components (Illenberger et al., 2011).

Table 2 Recruitment process

\begin{tabular}{|c|c|c|c|c|c|c|c|}
\hline & \multicolumn{2}{|c|}{$\begin{array}{l}\text { Whole } \\
\text { Sample }\end{array}$} & Seeds & $\begin{array}{l}\text { Iteration } \\
1\end{array}$ & $\begin{array}{l}\text { Iteration } \\
2\end{array}$ & $\begin{array}{l}\text { Iteration } \\
3\end{array}$ & Iteration 4 \\
\hline & Abs. & {$[\%]$} & Abs. & Abs. & Abs. & Abs. & Abs. \\
\hline Sample size & 4437 & & 275 & 568 & 1580 & 1589 & 425 \\
\hline Re-identified & 654 & & - & - & 247 & 227 & 180 \\
\hline Valid addresses & 2867 & 100.0 & 247 & 389 & 952 & 1012 & 267 \\
\hline Participated & 734 & 25.6 & 40 & 120 & 276 & 249 & 49 \\
\hline With recruitment & 657 & 22.9 & 40 & 106 & 249 & 220 & 42 \\
\hline $\begin{array}{l}\text { Without } \\
\text { recruitment }\end{array}$ & 77 & 2.7 & - & 14 & 27 & 29 & 7 \\
\hline
\end{tabular}

Considering the unusual survey methodology, high amount of response burden and level of confidentiality implied in the questions, the achieved response rate is satisfying. A rating system from commercial survey research (Weiss and Axhausen, 2010), assesses response burden by weighting each question according to its structure, predicts an instrument's response rate and helps qualify the multi-contact strategy. Figure 4 shows cooperation rate for two sub-samples from the survey; both include persons who received the questionnaire. The sub-sample 'with recruitment' received the whole multi-contact strategy, while those 'without recruitment' did not receive every step of the multi-contact strategy because no valid phone number was available for them. Instead, this second group received an announcement letter and, one week later, the questionnaire with the incentive and (if provided) the greeting card. The effect of the full multi contact strategy is clear. Persons 'with recruitment' show a cooperation rate over 60\%: those 'without recruitment' a cooperation rate of approximately $20 \%$. (Co- 
operation rate was calculated as the COOP4, number of persons agreeing to participate divided by participants, as suggested by AAPOR (2011)).

Figure 4 Effects of the multi-contact strategy (as of July, 2011)

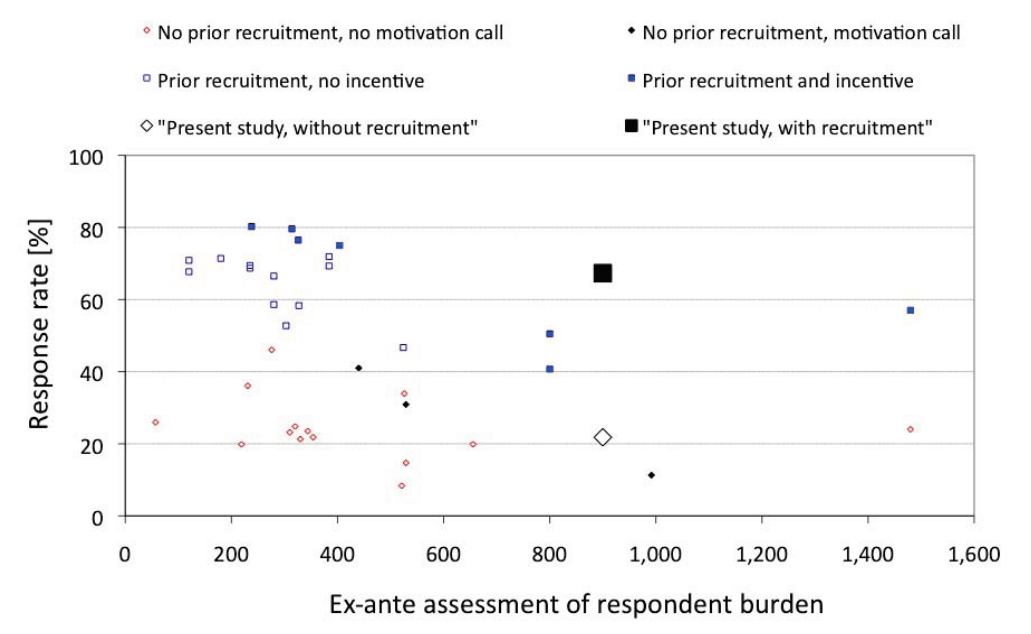

Source: Based on a current version of Axhausen and Weis (2010), with corrected weights for stated choice questions.

Both multi-contact strategy and greeting card can be used as explanatory variables in a 'decision to participate or to refuse' logistic regression model. The estimation shows the multi-contact strategy to be highly effective. Those respondents who received every contact are twice as likely to participate as those who received only partial contacts. The greeting card also has a significantly positive influence on participation.

Table 3 The influence of multi-contact strategy and greeting card on response rate

\begin{tabular}{lrrr}
\hline Coefficients & Estimate & Std. error & p-value \\
\hline Intercept & -1.246 & 0.134 & $<0.001$ \\
Dummy full multi-contact strategy & 2.004 & 0.151 & $<0.001$ \\
Dummy postcard & 0.345 & 0.162 & 0.033 \\
\hline Null deviance & 1643.9 & & \\
Residual deviance & 1424.5 & & $\mathrm{df}=1201$ \\
\hline
\end{tabular}

Modeling the incentive strategy effect is more difficult, as it was sent to all potential respondents. However, analyzing data from recruitment shows surprising results; a significant share of both respondents and non-respondents sent back the incentive. Employing a pivot table and a $\chi^{2}$-independence test shows a significantly different 
distribution than expected $\left(\chi^{2}=120.6 ; p=<0.001\right)$. Around $8 \%$ of all respondents and $33 \%$ of all non-respondents returned the incentive.

Table 4 Incentive and response behaviour

\begin{tabular}{|c|c|c|c|}
\hline & $\begin{array}{l}\text { Respon- } \\
\text { dents }\end{array}$ & $\begin{array}{l}\text { Nonrespon- } \\
\text { dents }\end{array}$ & Marginal frequencies \\
\hline Incentive kept & 666 & 362 & 1028 \\
\hline Incentive returned & 61 & 178 & 239 \\
\hline Marginal frequencies & 727 & 540 & $n=1267$ \\
\hline
\end{tabular}

Employing a logistic regression model on the decision whether to keep or return the incentive also indicates that this behavior is influenced by the multi contact strategy, which successfully primes people in a normative way. Having received all contacts increases the probability of returning the incentive. A negative effect results from response status (respondents or non-respondents) showing participants being less likely to return the incentive. The same is true when having received a greeting card (as the card increases the probability for participation). Socio-demographics are largely irrelevant, with the exception of age (we also checked marital status, level of education and sex). As respondents age, they are more likely to send back the incentive. The model is summarized in table 5.

Table 5 Logistic regression model on sending back the incentive

\begin{tabular}{lrrr}
\hline Coefficients & Estimate & Std. error & p-value \\
\hline Intercept & -1.758 & 0.348 & $<0.001$ \\
Dummy status of response & -1.888 & 0.179 & $<0.001$ \\
Dummy postcard & -0.427 & 0.214 & 0.046 \\
Dummy full multi-contact strategy & 0.617 & 0.183 & $<0.001$ \\
Age [years] & 0.016 & 0.007 & 0.013 \\
\hline Null deviance & 1178.0 & & \\
Residual deviance & 1040.0 & & $\mathrm{n}=1194$ \\
\hline
\end{tabular}




\section{Snowball sampling: Considerations of data treatment}

Using snowball sampling in a study of this size on personal leisure networks raises issues of data protection and ethical considerations. In the field, the survey was confronted with three major concerns. All of them have been checked by the Swiss Federal Data Protection and Information Commissioner (FDPIC). Naturally, personal data collection must always address issues of data security and anonymity. Furthermore, respondents must be made aware of their status as volunteer participants (even more crucial when using an incentive strategy), and the project goals.

First, like most studies on personal networks, the survey instrument included a name interpreter. This entails asking respondents about characteristics of third parties - their alters. Respondents usually have no idea that they (and some of their personal details) have been reported unless the ego tells them (Kadushin, 2005; Klovdahl, 2005). This problem is very acute in a snowball sample. The necessity of collecting data is accentuated here because alters' names and postal addresses are necessary to continue recruitment. However, the problem of collecting information on third parties is less critical in a snowball sample because all alters (at least those for whom valid addresses were available and for whom the ego allowed a contact) were asked to participate in the survey. So, almost all alters were informed about the survey study collecting data on them. Should an alter want information about which personal data were collected, this information had to be provided. In case the person wanted the data deleted, this had to be done as soon as possible. Both cases occurred in the present sample, but with 3 out of around 15.500 observations, only as very exceptional events.

Issues of data protection and anonymity are also relevant to a second topic. Usually, data are collected to allow calculation of anonymous statistics. In Switzerland, it is forbidden by law to collect personal data and use them in a personalized way. However, for this project, it was necessary to handle data both anonymously and personally. All alters had to be checked for re-identification and overlap between network components to avoid re-sampling. By employing two databases, one for recruitment and one for analysis, permanent distinction between these data was maintained. Only the recruitment database included names and addresses and they will be deleted after the study. This separation made it feasible to use snowball sampling in Switzerland. 
Regarding egos' anonymity, the Swiss Federal Data Protection and Information Commissioner (FDPIC) disagreed with the approach used in our study. If egos wished to remain anonymous, or did not sign greeting cards, their alters were not told who provided their name, even if they requested this information. Swiss law on data protection allows such exceptions to the general obligation of informing people what kind of data were collected on them and how this information was gathered, if the privacy of a third person is endangered. The FDPIC decided, however, that egos' wish to stay unmentioned is not sufficient reason for such exceptions. As this assessment was published after the study had been in the field, this project was not affected, but the topic must be addressed in future survey studies.

\section{Conclusions}

The paper introduced a methodology that allowed the use of snowball sampling to survey information on connected personal networks. To our knowledge, snowball sampling has never been used before in a study of this size and with so few restrictions on recruitment. Respondents were asked to mention leisure and emotionally important contacts. No further limitations were imposed, either on data collection or in recruitment.

The survey instrument's goal was to collect information on egos' and alters' characteristics, as well as on the ego-alter and alter-alter relationships. The paper introduced and explained in detail - both name generator and sociogram, which were particularly designed for this study. Wherever possible, we specified sources of bias and implemented design issues to keep bias source influence low.

Several arrangements were employed to decrease bias resulting from both snowball sampling and name generator. To avoid selection bias, survey, and recruit as many leisure contacts as possible, we employed a multi contact strategy, an incentive and a greeting card. The multi contact strategy had a particularly large positive impact on response rate by priming respondents in a normative way. This was very clear for the incentive, where a significant share of both non-respondents and respondents returned the form. As far as we know, such a phenomenon has seldom occurred before, or at least there is no literature documenting it. To increase the fit between sample and target population, we introduced a low-tech measure of starting snowball chains in two consecutive sub-samples. This helped balance bias in terms of over- and under- 
sampling. Finally, some related aspects of data security and ethics were introduced which must be considered when using snowball sampling.

In view of the fact that snowball samples rarely meet randomness criteria, we should note that the fit between sample and target population was surprisingly good, with only a few large cases of over- and underrepresentation. In addition, we not only observed connected components of personal networks, but also component overlaps in significant numbers (for detailed statistics on personal leisure networks and the global network see Kowald and Axhausen, forthcoming). In combination with our measures to decrease bias, this exceeded our expectations and resulted in a valuable data set. 


\section{Literature}

AAPOR (2011) Standard Definitions: Final Dispositions of Case Codes and Outcome Rates for Surveys, The American Association for Public Opinion Research.

Aarts, H., P.M. Gollwitzer and R.R. Hassin (2004) Goal contagion: Perceiving is for pursuing, Journal for personality and social psychology, 87 (1) $23-37$.

ARE/BfS (2007) Mobilität in der Schweiz, Ergebnissse des Mikrozensus 2005 zum Verkehrsverhalten. Federal Office for Spatial Development and Swiss Federal Statistical Office, Bern and Neuenburg.

Axhausen, K.W. and C. Weis (2010) Predicting response rate: A natural experiment, Survey Practice, 3 (2), http://surveypractice.org/2010/O4, accessed 12.08.2011.

Bell, D.C., B. Belli-McQueen and A. Haider (2007) Partner naming and forgetting: Recall of network members, Social Networks, 29, 279-299.

Campbell, K.E. and B.A. Lee (1991) Name generators in surveys of social networks, Social Networks, 13, 203-221.

Carrasco, J.A., E. J. Miller and B. Wellman (2008) How far and with whom do people socialize? Empirical evidence about the distance between social network members, Transporrtation Research Record, 2076, 114-122.

Chartrand, T.L. and J.A. Bargh (1999) The chameleon effect: The perception-behavior link and social interactions, Journal of Personality and social psychology, 76 (6) $893-$ 910.

Cialdini, R.B., R.R. Reno and C.A. Kallgren (1990) A focus theory of normative conduct: Recycling the concept of norms to reduce littering in public places, Journal of personality and social psychology, 58 (6) 1015-1026.

Coleman, J.S. (1958) Relational analysis: The study of social organizations with survey methods, Human Organization, 17 (4) 28 - 36.

Couper, M.P. and P.V. Miller (2008) Web survey methods: Introduction, Public Opinion Quarterly, 72 (5) 831-835.

Diekmann, A. and B. Jann (2001) Anreizformen und Ausschöpfquoten bei postalischen Befragungen. Eine Prüfung der Reziprozitätshypothese, ZUMA-Nachrichten, 48 (25) 18-27.

Dillman, D.A. (2000) Mail and Internet Surveys. The Tailored Design Method, Wiley \& Sons, New York.

Dunbar, R.I.M. (2003) The social brain: Mind, language, and society in evolutionary perspective, Annual Review of Anthropology, 32, 163-181. 
Erickson, B.H. (1979) Some problems of Inference from chain data, Sociological Methodology, 10 (1) $276-302$.

Fisher, C.S. (1982) To Dwell Among Friends: Personal Networks in Town and City, University of Chicago Press, Chicago.

Frei, A. and K.W. Axhausen (2007) Size and structures of social network geographies, Arbeitsberichte Verkehrs- und Raumplanung, 439, IVT, ETH Zurich, Zurich.

Frei, A. and K.W. Axhausen (forthcoming) Modelling the frequency of contacts in a shrunken world, Social Networks, forthcoming.

Frey, B.S. (1997) Not just for the money. An economic theory of personal motivation, Edward Elgar publishing company, Vermont.

Fu, Y.C. (2007) Contact diaries: Building archives of actual and comprehensive personal networks, Field Methods, 19 (2) $194-217$.

Gabler, S. (1992) Schneeballverfahren und verwandte Stichprobendesigns, ZUMANachrichten, 16 (31) 47-69.

Groves, R.M. (2004) Survey Errors and Survey Costs, Wiley, Hoboken.

Groves, R.M., F.J Fowler, M.P. Couper, J.M. Lepkowski, E. Singer and R. Tourangeau (2009) Survey Methodology, Wiley, Hoboken.

Heckathorn, D. (1997) Respondent-driven sampling: A new approach to the study of hidden populations, Social Problems, 44 (2) 174-199.

Heerwegh, D. and G. Loosveldt (2008) Face-to-face versus web surveying in a highinternet-coverage population. Differences in response quality, Public Opinion Quarterly, 72 (5) $836-846$.

Hogan, B., J. A. Carrasco and B. Wellman (2007) Visualizing personal networks: Working with participant-aided sociograms, Field Methods, 19 (2) $116-144$.

Illenberger, J. and G. Flötteröd (2011) Estimating properties from snowball sampled networks, VSP Working Paper,11-01, TU Berlin, Berlin.

Illenberger, J., M. Kowald, K.W. Axhausen and K. Nagel (2011) Insights into a spatially embedded social network from a large-scale snowball sample, The European Physics Journal B, http://www.springerlink.com/content/up74144648470723/, accessed 28.09.2011.

Jones, E.C. (2003) Class-based social networks in regional economic systems, Research in economic anthropology, 22 (1) 3-23.

Kadushin, C. (2005) Who benefits from network analysis: ethics of social network research, Social Networks, 27, $139-153$. 
Kleinberg, J.M. (2000) Navigation in a small world, Nature, 406, 845.

Klovdahl, A.S. (2005) Social network research and human subject protection: Towards more effective infectious disease control, Social Networks, 27, 119-137.

Knoke, D. and J.H. Kuklinski (1982) Network Analysis, Sage, Newbury Park.

Kochen, M. (1989) The Small World, Ablex, Norwood.

Kowald, M. (2010) Focussing on response behaviour from the perspective of goalframing theory, Arbeitsberichte Verkehrs- und Raumplanung, 616, IVT, ETH Zürich, Zürich.

Kowald, M., A. Frei and J. Hackney (2008) Spatial relationships and social networks: An iterative approach, paper presented at the ASNA Conference Zurich 2008, Zurich, September 2008 and the $8^{\text {th }}$ Swiss Transport Research Conference, Ascona, October 2008.

Kowald, M., A. Frei, J.K. Hackney, J. Illenberger and K.W. Axhausen (2009a) Collecting data on Leisure Travel: The Link between Leisure Acquaintances and Social Interactions, Conference Paper for "Applications of Social Network Analysis" (ASNA), Zurich, 2009.

Kowald, M., A. Frei, J.K. Hackney, J. Illenberger and K.W. Axhausen (2009b) Using an ascending sampling strategy to survey connected egocentric networks: A field work report on phase one of the survey, Arbeitsberichte Verkehrs- und Raumplanung, 582, IVT, ETH Zurich, Zurich.

Kowald, M., A. Frei, J.K. Hackney, J. Illenberger and K.W. Axhausen (2009C) The influence of social contacts on leisure travel: A snowball sample of personal networks, paper presented at the $12^{\text {th }}$ International Conference on Travel Behaviour Research, Jaipur, December 2009.

Kowald, M., A. Frei, J.K. Hackney, J. Illenberger and K.W. Axhausen (2010) Collecting data on Leisure Travel: The Link between Leisure Acquaintances and Social Interactions, Procedia - Social and Behavioral Sciences, 4 (1) 38-48.

Kowald, M., J.K. Hackney and A. Frei (2008) Mögliche Vorgehensweisen zur Erhebung sozialer Netzwerkdaten durch die iterative Kombination ego-zentrierter Netzwerke, Arbeitsberichte Verkehrs- und Raumplanung, 506, IVT, ETH Zürich, Zürich.

Kowald, M. and K.W. Axhausen (forthcoming) Focussing on connected personal net networks: Selected results from a snowball sample, Environment and Planning A.

Kowald, M. und K.W. Axhausen (2010a) Egos' horizons and behind it: Snowball sampling of personal leisure networks, in M. Grieco and J. Urry (eds.) Mobilities: New Perspectives on Transport and Society, Ashgate, Farnham. 
Kowald, M. and K.W. Axhausen (2010b) The structure and spatial spread of egocentric leisure networks, Conference Paper for Applications of Social Network Analysis (ASNA), Zurich, 2010.

Kowald, M. and K.W. Axhausen (2011) Strong and weak relationships: Tie strengths in egocentric leisure networks, Conference Paper for the $106^{\text {th }}$ American Sociological Association Annual Meeting, Chicago, August 2011.

Kowald, M. and T. Arentze (2010) Dealing with hierarchically clustered data: Missing value analyses and imputations, Arbeitsberichte Verkehrs- und Raumplanung, 656, IVT, ETH Zürich, Zürich.

Larsen, J., J. Urry and K.W. Axhausen (2006) Mobilities, Networks, Geographies, Ashgate, Aldershot.

Lindenberg, S., D. Fetchenhauer, A. Flache and A.P. Puunk (2006) Solidarity and prosocial behavior: A framing approach, in D. Fetchenhhauer, A. Flache, A.P. Buunk and S. Lindenberg (eds.) Solidarity and prosocial behavior. An integration of sociological and psychological perspectives, 3 -19, Springer, Waterloo.

Lindenberg, S. (2006) Prosocial behavior, solidarity, and framing processes, in D. Fetchenhhauer, A. Flache, A.P. Buunk and S. Lindenberg (eds.) Solidarity and prosocial behavior. An integration of sociological and psychological perspectives, 23 -44, Springer, Waterloo.

Lindenberg, S. (2008) Social rationality, semi-modularity and goal-framing: What is it all about?, Analyse \& Kritik, 30 (1) 669-687.

Mamali, C. (2006) Contextual pictorial representations of self-others relationships: The social autograph technique, http://www.self.ox.ac.uk/Conferences/2006/Mamali.pdf, August, 1th, 2011.

Marsden, P.V. (1987) Core discussion networks of Americas, American Sociological Review, 52, 122-131.

Marsden, P.V. (1990) Network data and measurement, Annual Review of Sociology, 16, 435-463.

Mathews C., N. Coetzee, M. Zwarenstein, C. Lombard, S. Guttmacher, A. Oxman and G. Schmid (2001) Strategies for partner notification for sexually transmitted diseases, Cochrane database of systematic reviews, 2, Wiley, the Cochrane library.

Matzat, U. and C. Snijders (2010) Does the online collection of ego-centred network data reduce data quality? An experimental comparison, Social Networks, 32 (2) 105-111.

McPherson, M., L. Smith-Lovin and J.M. Cook (2001) Birds of a feather: Homophily in social networks, Annual Review of Sociology, 27, 415- 444. 
McPherson, M., L. Smith-Lovin and M.E. Brashears (2006) Social Isolation in America: Changes in core discussion networks over two decades, American Sociological Review, 71 (3) 353-375.

Milgram, S. (1967) The small world problem, Psychology today, 1 (1) 61-67.

Pool, I. and M. Kochen (1978) Contacts and Influence, Social Networks, 1, 5-51.

Pustejovsky, J.E. and J.P. Spillane (2009) Question order effects in social network name generators, Social Networks, 31, 221-229.

Roberts, S.G.B., R.I.M. Dunbar, T.V. Pollet and T. Kuppens (2009) Exploring variation in active network size: Constraints and ego characteristics, Social Networks, 31, 138146.

Salentin, K. (1999) Die Stichprobenziehung bei Zuwandererbefragungen, ZUMANachrichten, 23 (45) $115-135$.

Schlich, R., S. Schönfelder, S. Hanson and K.W. Axhausen (2004) Structures of leisure travel: Temporal and spatial variability, Transportation Review, 24 (2) $219-228$.

Schnettler, S. (2009a) A structured overview of 50 years of small-world research, Social Networks, 31, 165-178.

Schnettler, S. (2009b) A small world on feet of clay? A comparison of empirical small world studies against best-practice criteria, Social Networks, 31, 179-189.

Schweizer, T., M. Schnegg and S. Berzborn (1998) Personal networks and social support in a multiethnic community of southern California, Social Networks 20, 1-21.

Scott, J. (2007) Social Network Analysis. A Handbook, Sage, Thousand Oaks.

Sen, S. and S. Bricka (2009) Data collection technologies - Past, present, and future, Conference Paper for the $12^{\text {th }}$ Meeting of the International Association for Travel Behaviour Research, Jaipur.

Silvis, J., D. Niemeier and R. D'Souza (2006) Social networks and travel behaviour: Report from an integrated travel diary, Conference Paper for the $11^{\text {th }}$ International Conference on Travel Behaviour Research, Kyoto.

Van den Berg, P.E.W., T.A. Arentze and H.J.P. Timmermans (2007) Social networks, ICT use and activity travel patterns in different spatial settings: Data collection instrument and first results, Conference Paper for Proceeding of the Frontiers in Transportation 2007, Amsterdam.

Van den Berg, P.E.W., T.A. Arentze and H.J.P. Timmermans (2011) A multilevel path analysis of contact frequency between social network members, Journal of Geographical Systems, http://www.springerlink.com/content/c4615g56u5831263/, August, 14th, 2011. 
Wasserman, S. and K. Faust (2007) Social Network Analysis: Methods and Applications, Cambridge University Press, Cambridge.

Wellman, B. (1979) The community question: The intimate networks of East Yorkers, American Journal of Sociology, 84, 1201-1231.

Wolf, M. (2004) Egozentrierte Netzwerke: Erhebungsverfahren und Datenqualität, Kölner Zeitschrift für Soziologie, Sonderheft 44, 244-273. 